Check for updates

The BMJ

Cite this as: BMJ 2021;374:n2081 http://dx.doi.org/10.1136/bmj.n2081 Published: 23 August 2021

\title{
Should I take an "F3" year?
}

\section{Taking a break between foundation and specialty training offers opportunities to gain experience and work in different areas, Abi Rimmer hears}

Abi Rimmer

\section{It's a chance to stop and reflect}

Helen Chidera Ota, surgical teaching fellow, says, "For a lot of doctors, an F3 year is the first real 'break' they may have had since entering education. It's very easy to rush through school, university, and foundation training with a focus on jumping through hoops and passing assessments as we go. But time to stop, reflect on what you've experienced, and make thoroughly thought out plans for the future is rare. And that's where an F3 may be useful.

"It's time outside of the strict constraints of formal education or training, to focus on what you actually want. This could be more experience in specialties you're yet to try as a doctor-to give you a better idea of whether you're well suited to them or need to rule them out of future plans. It can also be time to build your portfolio.

"This can seem like a tick box exercise but gaining extra experience, whether through courses, exams, or exposure to a job as a trust grade, can be incredibly rewarding in building your confidence and clinical acumen, allowing you to feel better prepared for specialty training.

"The flexibility of an F3 is something that is rarely found in training. This is a great time to do the things that you may struggle to do as a trainee, whether that be travelling, volunteering, or even crossing off some milestones in your personal life, like getting married or having a baby. Essentially your $\mathrm{F}_{3}$ is a year to make entirely what you want of it. A rare opportunity to focus on exactly what you want and one that you'll likely look back on fondly for years to come. Enjoy it.”

\section{"It can boost clinical experience"}

Rose Dhesi, consultant anaesthetist and F3 training programme director, Imperial NHS Trust, says, “As a consultant anaesthetist and educator, I noticed that most of our core trainees were not coming to us straight after their foundation training. This reflected my own training 20 years ago. I obtained experience in paediatrics before anaesthetic training, others did medicine or surgery, and it was considered the norm.

"Not everyone is sure, after foundation training, which specialty they want to go into. For others, the idea of going straight on to a training programme is daunting. This time represents an opportunity to explore other avenues.

"When my trust advertised a new role for a F3 training programme director I jumped at the chance. In my opinion it was a project that was in tune with the needs of junior doctors. We had the support of the trust to build a programme that allowed us to be flexible and responsive to the needs of the current workforce.

“There are benefits for trainees in taking an F3 year instead of another non-training post. On our programme we support them with their pay, HR, rotas, study leave, and a study budget. Trainees can opt to choose a six month post starting in August or February, or they can choose two six month posts in different specialties, some without on-calls.

"The benefits for trainees are enormous. An F3 year allows them more time to boost core training applications and increase their clinical experience. In some core training applications points are awarded for time spent in other specialties which increase if competencies have been achieved.

"Finally, when I started as F3 training programme director two years ago my first August appointments numbered around seven, this year we are up to 60 . This demand proves an F3 year has value and is of benefit to our junior doctors."

\section{There is no rush to get through training}

Kevin Tsang, consultant craniofacial and neurosurgeon and unit training lead, Imperial NHS Trust, says, "It's not always easy to decide on your career path. Not every medical student comes out of medical school knowing exactly which specialty they want to do and it is not surprising that many change their minds once they've actually worked in the specialty as a junior doctor.

"Observing from the side and attending all the 'interesting' events is very different to being the ward doctor day in and day out. As good as the foundation training programme is, new doctors only get a short four months taste of a few specialties. Some may develop special interests during this time while others can still be undecided.

“An F3 year gives trainees extra experience in specialties of their choice, to reinforce their career goals. It also gives them time for portfolio development to show commitment to specialty. National selection is competitive for all specialties, so extra experience and academia along with maturity at interview go a long way.

"There is also no rush to get through training. Being a clinician in any discipline is about experience and integration with the team. Speeding through training to get to the end isn't necessarily the marker of a successful doctor and certainly not always the best way to produce the best clinicians.

"We have had excellent experience with our F3 programme. In terms of service provision, these 
trainees are experienced registrars who add to our multidisciplinary team. From a training point of view, they have a dedicated supervisor and flexibility in terms of specialty choices to support their next training post application. All-in-all it has worked very well for both sides."

\section{It can increase your confidence}

Dara Rasasingam, internal medicine training trainee, London, says, "There are many reasons why the F3 year is valuable. It allows more autonomy in your personal and professional life and enables you to explore your own interests.

"This was important for me, as my academic foundation programme was tailored towards becoming a GP and I didn't anticipate falling in love with hospital medicine. My F3 year allowed me to choose medical jobs and improve my clinical skills and increase confidence in practical procedures.

"An F3 year offers flexibility and the ability to work 9-5 while keeping your practical and clinical skills up to date. It can allow time to rest and recharge. I was able to buy my first house, renovate it, and plan my wedding. These personal milestones have been much more achievable as an F3.

“There are downsides of taking an F3 year so it's not for everyone. Taking time out prolongs the time before you're a consultant or GP. You have to be proactive and you're responsible for setting your own personal development goals and for your annual appraisal.

"Whether an F3 year is for you is a personal decision. Although it's not a formal part of training, it can be enriching in many ways. For me, it's been a great stepping stone in achieving my first choice job and my future career.” 